\title{
Impact of Wearing Two Different Types of Partial Dentures on Oral Health-related Quality of Life in Geriatric Diabetic Patients - A Crossover Study
}

\author{
Eman M. Ibraheem, Hisham EIGabry* \\ Department of Prosthodontics, National Research Centre, Egypt
}

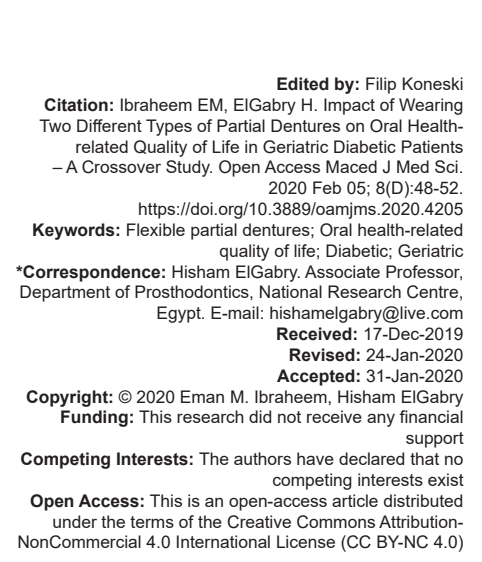

Introduction

Quality of life lately was defined as "the degree to which a person enjoys the important possibilities of life." Quality of life is not strictly objective, it also has subjective elements. Oral health-related quality of life (OHRQoL) was defined as "a multidimensional and selfreported assessment that measures the impact of oral conditions on daily activities." It is used to assess the health of oral cavity, as a guide for arranging resource investment, to measure the effectiveness of oral health interferences and the outcomes of dental maintenance in groups of elderly people [1].

Oral diseases can affect the quality of life and also the status of oral health can affect people psychologically and physically, speech, chewing, food tasting, and socialization. As oral status can be greatly affected by loss of natural teeth, esthetics and social communication may be more important than chewing and may be the most prime goal of partially edentulous patients requiring replacement of their lost teeth. This situation frequently occurs in elderly patients. Thus, the prosthodontists should be more concerned about oral health of this group [2].
Diabetes mellitus (DM) is a chronic endocrinal metabolic disorder that is becoming worldwide one of the most interesting rapidly growing health diseases. DM occurs when the pancreatic beta cells are not producing sufficient insulin in the blood circulation or when the human body is unable to effectively utilize the secreted insulin [3].

Diabetes is a chronic disorder which markedly affects the dentate individuals and routine life activity of partially edentulous patients. Furthermore, it was observed that dissatisfaction of oral health was associated with a poorer quality of life. Furthermore, dissatisfaction linked to dental health condition and dry mouth feeling was greater for diabetic patients compared to non-diabetic people [3], [4]

Meanwhile, very few studies were concerned with OHRQoL of diabetic patients which is considered a very important element of patient outcome. Usually, OHRQoL used for evaluating patient outcomes, but they have not been developed mainly for diabetic patients [5]. Thus, due to the importance of the close link between diabetes and oral health complications, it is essential to study and understand the influence of oral health status on OHRQoL in diabetic patients through providing superior dental care [3]. 
Nevertheless, few treatment options have proven to be effective for partially edentulous geriatric patients, other than fixed implant restorations. On the other hand, the most conservative treatment option in rehabilitating these patients are removable partial dentures (RPD) as they provide pleasing esthetics, satisfactory mastication, acceptable speech, and selfconfidence, respectively [6].

Lately, flexible partial dentures provide excellent esthetics and comfort providing years of satisfactory service for diabetic partial denture wearers and improving the level of patients' self-confidence and thus the quality of their life [7].

This study was conducted to evaluate the relative impact of restoring edentulous spaces in diabetic geriatric patients with flexible RPDs (FRPDs) and its positive effect on OHRQoL of those patients to help promoting oral health and improve dental care for those patients.

\section{Aim of this study}

This study aimed to evaluate the OHRQoL of partially edentulous elderly diabetic patients before and after wearing heat-cured acrylic resin and FRPDs.

\section{Materials and Methods}

One hundred patients were invited to participate in this study, $93 \%$ of them agreed and $70 \%$ completed the study. All patients had partially edentulous mandibular Class I Kennedy's classification (bilateral free end). Diabetic elderly patients were selected from the Prosthodontics Department in the Excellence Centre, National Research Centre (NRC). Some of the enrolled patients had participated in a previous research funded by the same project. All patients were controlled type II $\mathrm{DM}$, males, ranging from 50 to 65 years old, non-smokers, and they were not receiving any medication other than the oral hypoglycemic treatment. Medical records for all patient included in the study were performed concerning the fasting serum glucose level that was higher than $126 \mathrm{mg} / \mathrm{dl}$ as well as the glycosylated hemoglobin level does not exceed $7.5 \%$ at the beginning of the study and through all the study period. Patient's examination was made including extra- and intra-oral examination, panoramic radiograph, and diagnostic casts. Moreover, the selected patients were skeletally Angle's Class I and the edentulous alveolar ridges were covered by firm mucoperiosteum.

\section{Ethical considerations}

At beginning of the study, patient's data (personal, medical, and dental) were collected according to the implemented rules of research ethical committee of NRC, and written consents were obtained from the participating patients.

All patients were informed about the practical steps of this study and the follow-up period and they signed the approval consents. This study was approved by the Ethics Committee of NRC (Approval No. 16-086).

\section{Materials}

The materials used in the study were alginate impression material (Cavex CA37: Cavex Holland BV, Holland), plaster of Paris (Moldano, Bayer, W. Germany), auto-cure acrylic resin (Acrostone, England), rubber base elastomeric impression materials (Coltene, Whaledent, Speedex, Switzerland), pink wax (Cavex Holland BV, Haarlem, Noord-Holland, Netherlands), modified anatomic acrylic resin artificial teeth (Acrostone Dental and Medical Supplies, Cairo, Egypt), heat-cured acrylic resin (Acrostone Dental and Medical Supplies, Cairo, Egypt), flexible acrylic resin "Versacryl" (Keystone Industries $\mathrm{GmbH}$, Siegen, Germany), nylon (bre.flex2), and CHROMagar Candida (CHROMagar, France). The instruments utilized were face bow (Whip Mix \#8645 Quick Mount, Louisville, KY, U.S.A.) and semi-adjustable articulator (Hanau, Model $\mathrm{H}$, Teledyne, Buffalo, NY, USA).

\section{Prosthodontic procedures}

Every patient had received two partial dentures. The first denture was heat-cured acrylic resin and the second denture was flexible partial dentures. The mandibular thermoplastic nylon bilateral free-end saddle partial denture, evidently, the injection molding technique was implemented for processing of the thermopress partial denture. Initially, the Start-Heating key was pressed to start liquefying the nylon polymer crystal cartridge to $222^{\circ} \mathrm{C}$ for $15 \mathrm{~min}$. After complete softening of the nylon crystals, the Start-Injection key was activated aiming to press the thermoplastic polymer material throughout the sprue channel into the denture mold of the flask.

Whenever the injection technique was completed, the system had stopped for minutes; then, the machine piston was moving backward and the flask was removed from the injection molding machine by pushing the Eject key. After deflasking of the denture, finishing and polishing at low speed using thermal resin finishing burs and pumice was made. Finally, buffing was done to give a very high luster to the denture and they were ready for insertion.

\section{Evaluation criteria}

The OHRQoL was assessed using the "Oral Health Impact Profile-14" (OHIP-14) [8]. 
Two trained operators clarified the questionnaire to the patients and remained by their side to reply any possible suspicions. The OHIP-14 was applied at three different times: (1) During the first visit at the clinic, just before receiving the new dentures, to assess the quality of life before the treatment (pre-operative record 1), (2) during a follow-up visit, 3 months after the installation of the heat-cured acrylic resin denture (record 2), and (3) during a follow-up visit, 3 months after the installation of the flexible partial dentures (record 3) (Figure 1).

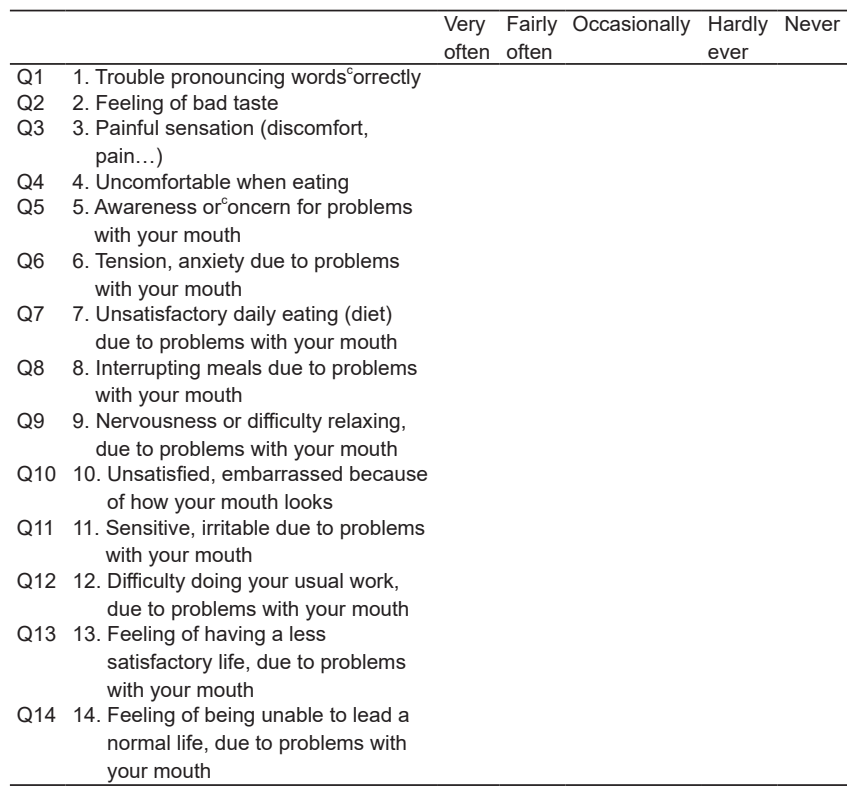

Figure 1: The oral health impact profile-14 that we used

\section{Statistical analysis}

Data were statistically analyzed by $20 \mathrm{GraphPad}$ Prism and Windows Excel and presented as mean and standard deviations and $p=0.05$ (significant level).

\section{Results}

The means of this scored questionnaire ranged from 1 (very often) to 5 (never).

Before denture insertion (record 1 ), the lowest mean score was in Q10 (1.1) while the highest mean score was in $Q 2$ (2.6). After insertion of heat-cured acrylic resin partial denture (record 2), the mean scores increased and $Q 10$ remains the lowest mean score (2.5) while $Q 11$ was the highest mean score (3.8), while after insertion of flexible partial denture (record 3 ) also, all means increased and $Q 7$ is the lowest mean (3.7) and the highest mean was in Q 14 (4.6), as presented in Table 1 and Figure 2.

Comparisons were performed between scores before denture insertion (record 1), after insertion of heat-cured acrylic resin partial denture (record 2),

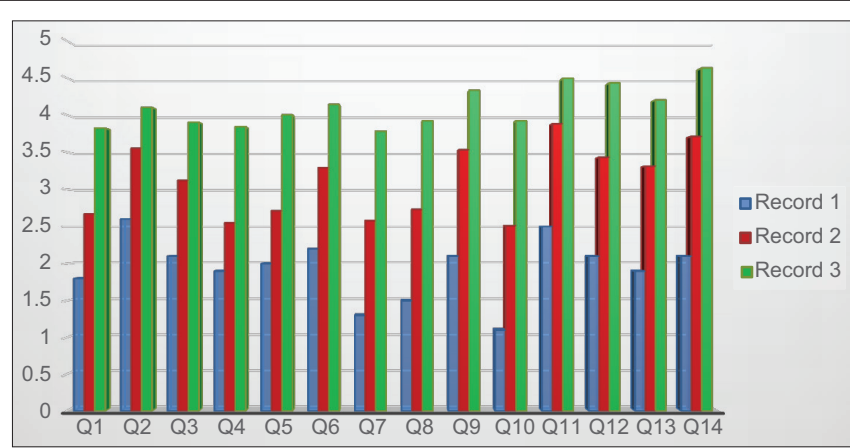

Figure 2: Bar chart represents mean score before (record 1) and after wearing the heat-cured acrylic (record 2) and flexible removable partial dentures (record 3) in the oral health impact profile-14)

and after insertion of flexible partial denture (record 3) by one-way ANOVA test which revealed significant difference $(p<0.05)$ regarding all questions followed by Tukey's post hoc test for multiple comparisons which revealed significant difference between all groups as $p<0.05$ (means with different superscript letters), as presented in Table 1.

Table 1: Score means before (record 1) and after wearing the heat-cured acrylic (record 2) and flexible removable partial dentures (record 3) in the oral health impact profile-14

\begin{tabular}{|c|c|c|c|c|c|c|c|}
\hline \multirow[t]{2}{*}{ Question number } & \multicolumn{2}{|c|}{ Record 1} & \multicolumn{2}{|c|}{ Record 2} & \multicolumn{2}{|c|}{ Record 3} & \multirow[t]{2}{*}{$p$ value } \\
\hline & $\mathrm{M}$ & SD & $M$ & SD & $M$ & SD & \\
\hline Q1 & 1.8 & 0.87 & 2.6 & 0.98 & 3.8 & 0.70 & $0.0001^{*}$ \\
\hline Q2 & 2.6 & 0.81 & 3.5 & 0.91 & 4.1 & 0.74 & $0.0004^{*}$ \\
\hline Q3 & 2.1 & 0.79 & 3.1 & 0.87 & 3.9 & 0.68 & $0.0001^{*}$ \\
\hline Q4 & 1.9 & 0.52 & 2.5 & 0.89 & 3.8 & 0.75 & $0.0001^{*}$ \\
\hline Q5 & 2.0 & 0.68 & 2.7 & 0.91 & 4.0 & 0.71 & $0.0001^{*}$ \\
\hline Q6 & 2.2 & 0.61 & 3.2 & 1.10 & 4.1 & 0.84 & $0.0001^{*}$ \\
\hline Q7 & 1.3 & 0.54 & 2.5 & 0.89 & 3.7 & 0.92 & $0.0001^{*}$ \\
\hline Q8 & 1.5 & 0.58 & 2.7 & 0.91 & 3.9 & 0.79 & $0.0001^{*}$ \\
\hline Q9 & 2.1 & 0.71 & 3.5 & 0.93 & 4.3 & 0.80 & $0.0001^{*}$ \\
\hline Q10 & 1.1 & 0.48 & 2.5 & 0.96 & 3.9 & 0.73 & $0.0001^{*}$ \\
\hline Q11 & 2.5 & 0.71 & 3.8 & 0.88 & 4.4 & 0.65 & $0.0001^{*}$ \\
\hline Q12 & 2.1 & 0.65 & 3.4 & 0.98 & 4.4 & 0.68 & $0.0002^{*}$ \\
\hline Q13 & 1.9 & 0.62 & 3.3 & 0.94 & 4.2 & 0.79 & $0.0001^{*}$ \\
\hline Q14 & 2.1 & 0.71 & 3.7 & 0.94 & 4.6 & 0.53 & $0.0001^{*}$ \\
\hline
\end{tabular}

M: Means, SD: Standard deviations, p: Probability level $(0.05)$, ${ }^{*}$ Significant difference $(p \leq 0.05)$

\section{Discussion}

Evaluation of OHRQoL in the elderly was carried out using OHIP-14. OHIP-14 is a short questionnaire that has 14 questions that focus on pain, functional restriction, psychological irritability, psychological and physical disability, social incapacity, and handicap. OHIP-14 is advantageous for patient's obedience and easiness when compared with longer detailed questionnaires. That is why the OHIP has been preferred for our study [9], [10].

Nikbin et al. and Rao et al. proposed that increased psychological tension will have an effect on the nervous system and thereby increasing glucagon secretion and increases serum glucose levels. In our study, diabetics had more psychosocial effect in addition to similar impact (i.e. ache, functional restriction, social and psychological, and limitation) [11], [12], [13]. 
General oral health assessment index (GOHAI) presented more dependable in defining discomfort, pain, and psychosocial impact, while OHIP-14 was more precise for defining pain and psychological discomfort. Others concluded that GOHAl has high ability in determining difficult function, discomfort, and pain, whereas the OHIP-14 was to detect additional social and psychological problems and physical limitations [14].

Several studies have concluded a significant relation between denture quality and the indicators of individual oral health status such as "chewing limitation" and "speech problems." Furthermore, compromised oral condition had negative effect on OHRQoL in diabetics, leading to pain and difficult mastication, decreased self-esteem, and poor self-confidence. Underlining the meaning of oral health for diabetic patients could help in improving oral health-related life quality to a great extent. Furthermore, lesser quality of life experienced by diabetics diminishes dental and prosthetic management [11], [15].

There was a positive relationship between the denture quality and OHRQoL. The stability of denture was considerably linked with the OHRQoL mental health, meaning that superior quality of the denture was related to better mental health [16], [17].

Our results regarding the use of FRPDs status and its impact on OHRQoL suggest that teeth loss has a great influence on OHRQoL. Alteration from being partially edentulous to having FRPD is a significant stage for their psychosocial and oral functional comfort of elderly patients [18].

The use of FRPDs improved the OHRQoL obviously. Our findings were in agree with Montero et al., who made prosthetic treatment for some Spanish patients, whose mean OHIP scores decreased from $18.8 \pm 12.7$ (baseline) to $1.9 \pm 3.9$ after the use of acrylic partial denture. Likewise, in a study comparing acrylic and flexible partial dentures, participants' satisfaction was outstanding after the use of FRPDs [7], [19].

The improvement in OHRQoL with the use of flexible prosthesis may be attributed to easier chewing and mastication, clear pronunciation, natural esthetic appearance, and positive psychological and social interaction. Hence, thermoplastic materials should be considered as an alternative RPD base material in treatment planning for elderly patients [7], [20].

\section{Conclusions}

Within the limitation of this study, it could conclude that:

1. Dental prostheses had a positive influence on OHRQoL of all participants

2. For all participants, the OHRQoL was improved after using the flexible partial dentures
3.

Denture satisfaction was the strongest predictor feature and it is suggested for evaluating the outcome of dental treatment on OHRQoL of aged individuals wearing RPDs.

\section{Acknowledgments}

The authors thank the NRC, Cairo, Egypt, for supporting and funding this study that was derived from a project entitled "Dental care to improve quality of life for diabetic geriatric patients" project no. 21010203 (2016-1019).

\section{References}

1. Sanders AE, Slade GD, Lim S, Reisine ST. Impact of ora disease on quality of life in the US and Australian populations. Community Dent Oral Epidemiol. 2009;37(2):171-81. https://doi. org/10.1111/j.1600-0528.2008.00457.x

PMid:19175659 PMCid: PMC3760707

2. Hebling E, Pereira AC. Oral health-related quality of life: A critical appraisal of assessment tools used in elderly people. Gerodontology. 2007;24(3):151-61. https://doi. org/10.1111/j.1741-2358.2007.00178.x

PMid:17696892

3. Sandberg GE, Wikblad KF. Oral health and health-related quality of life in type 2 diabetic patients and non-diabetic controls. Acta Odontol Scand. 2003;61(3):141-8. https://doi. org/10.1080/00016350310002559

PMid:25587385 PMCid: PMC4288913

4. Azogui-Lévy S, Dray-Spira R, Attal S, Hartemann A, Anagnostou F, Azerad J. Factors associated with oral healthrelated quality of life in patients with diabetes. Aust Dent J. 2018;63(2):163-9. https://doi.org/10.1111/adj.12577 PMid:29140554

5. Irani FC, Wassall RR, Preshaw PM. Impact of periodontal status on oral health-related quality of life in patients with and without Type 2 diabetes. J Dent. 2015;43(5):506-11. https://doi. org/10.1016/j.jdent.2015.03.001

PMid:25769264

6. Wismeijer D, Tawse-Smith A, Payne AG. Multicentre prospective evaluation of implant-assisted mandibular bilateral distal extension removable partial dentures: Patient satisfaction. Clin Oral Implants Res 2013;24(1):20-7. https://doi. org/10.1111/j.1600-0501.2011.02367.x

PMid:22111809

7. Akinyamoju CA, Dosumu OO, Taiwo JO, Ogunrinde TJ, Akinyamoju AO. Oral health-related quality of life: Acrylic versus flexible partial dentures. Ghana Med J. 2019;53(2):163-9. https://doi.org/10.4314/gmj.v53i2.12

PMid:31481813

8. Slade GD. Derivation and validation of a short-form oral health impact profile. Community Dent Oral Epidemiol. 1997;25(4):28490. https://doi.org/10.1111/j.1600-0528.1997.tb00941.x

PMid:9332805

9. El Osta N, Tubert-Jeannin S, Hennequin M, Bou Abboud 
Naaman N, El Osta L, Geahchan N. Comparison of the OHIP-14 and GOHAl as measures of oral health among elderly in Lebanon. Health Qual Life Outcomes. 2012;10:131. https://doi. org/10.1186/1477-7525-10-131

PMid:23110518 PMCid: PMC3495839

10. Yen YY, Lee HE, Wu YM, Lan SJ, Wang WC, Du JK, et al. Impact of removable dentures on oral health-related quality of life among elderly adults in Taiwan. BMC Oral Health. 2015;15:1. https://doi.org/10.1186/1472-6831-15-1

PMid:25559722 PMCid: PMC4298049

11. Nikbin A, Bayani M, Jenabian N, Khafri S, Motallebnejad M. Oral health-related quality of life in diabetic patients: Comparison of the persian version of geriatric oral health assessment index and oral health impact profile: A descriptive-analytic study. J Diabetes Metab Disord. 2014;13(1):32. https://doi. org/10.1186/2251-6581-13-32

PMid:24495383 PMCid: PMC4015305

12. Rao A, Shenoy R, Rao A. Impact of periodontal health on the quality of Life among diabetics. Int J Adv Res. 2014;2(6):608-13.

13. Ibraheem E, El-Sisy EE. Comparing the effect of three denture adhesives on the retention of mandibular complete dentures for diabetic patients (randomized clinical trial). Bull Natl Res Cent. 2019;43:24. https://doi.org/10.1186/s42269-019-0052-7

14. Ikebe K, Hazeyama T, Enoki K, Murai S, Okada T, Kagawa R, et al. Comparison of GOHAl and OHIP-14 measures in relation to objective values of oral function in elderly Japanese. Community Dent Oral Epidemiol. 2012;40(5):406-14. https://doi. org/10.1111/j.1600-0528.2012.00683.x

PMid:22469135
15. Goguta L, Lungeanu Jivanescu DA. Removable denture treatment satisfaction of patients with Type-2 diabetis. J Diabetes Nutr Metab Dis. 2018;25(3):277-82. https://doi. org/10.2478/rjdnmd-2018-0032

16. Inukai $\mathrm{M}$, Baba $\mathrm{K}$, John $\mathrm{MT}$, Igarashi $\mathrm{Y}$. Does removable partial denture quality affect individuals' oral health? J Dent Res. 2008;87(8):736-9. https://doi org/10.1177/154405910808700816

PMid: 18650544

17. Heydecke G, Locker D, Awad MA, Lund JP, Feine JS. Oral and general health-related quality of life with conventional and implant dentures. Community Dent Oral Epidemiol. 2003;31(3):161-8. https://doi.org/10.1034/j.1600-0528.2003.00029.x PMid:12752541

18. Anjum MS, Monica M, Rao KY, Reddy PP, Hameed IA, Jyothi M. Does tooth loss have an emotional effect? A crosssectional and comparative study on non-denture wearers and complete denture wearers. J Indian Assoc Public Health Dent. 2017;15(3):247-51. https://doi.org/10.4103/jiaphd.jiaphd_46_17

19. Montero J, Castillo-Oyagüe R, Lynch $C D$, Albaladejo $A$, Castaño A. Self-perceived changes in oral health-related quality of life after receiving different types of conventional prosthetic treatments: A cohort follow-up study. J Dent. 2013;41(6):493503. https://doi.org/10.1016/j.jdent.2013.01.006 PMid:23353070

20. Motallebnejad M, Hadian $\mathrm{H}$, Mehdizadeh S, Hajiahmadi M Validity and reliability of the Persian version of the oral health impact profile (OHIP)-14. Caspian J Intern Med. 2011;2(4):314-20.

PMid:24551438 PMCid: PMC3895829 